\title{
DIGNIDADE E DEVER MORAL NA FUNDAMENTAÇÃO DA METAFÍSICA DOS COSTUMES DE KANT
}

Dignity and moral duty in Kant's Grounding for the Metaphysics of Morals

\author{
Erisvanda Campos da Costa ${ }^{1}$ \\ Silmara Natifate da Silva Lima ${ }^{2}$
}

RESUMO: O presente trabalho destaca a relação entre dignidade e dever moral como qualidade e valor que identifica o homem autônomo. Dessa forma, o conceito de liberdade e do agir moral são relevantes para demonstrar o sentido do agir livre a partir da ação por dever, não por afetos, mas sim por leis internas racionais, autônomas. O homem em sua dignidade não pode ser tratado como meio para uma finalidade, mas como fim em si mesmo, pois se considera a condição de leis a priori na ação puramente moral no valor que é sua dignidade.

Palavras-chaves: Dignidade. Dever. Moral. Liberdade. Autonomia.

ABSTRACT: The present paper highlights the connection between dignity and moral duty as a quality and valor that identify the autonomous man. This way, the concept of freedom and moral acting are relevant to present the sense of free acting from the action by duty and not by affection, but instead by internal, rational and autonomous laws. Man, in their dignity, cannot be treated as means to an end, but as an end on themselves because the valor of their dignity is considered the condition to a priori laws for the purely moral action.

Key-words: Dignity. Duty. Moral. Freedom. Autonomy.

\section{INTRODUÇÃO}

A concepção de dignidade e de dever moral em Kant, parte do exame das propriedades intrínsecas e próprias do homem, que se manifestam a priori na racionalidade prática, como condição de determinação da ação, consonante a consciência de si mesmo, que pode está livre de determinação externa. O querer como vontade precisa ser determinado de modo puro para que venha tornar-se um querer em si, sem ser objeto de interesse particular do sujeito, mas sim que seja promoção do querer por si mesmo. O dever, por sua vez é uma ação moral

\footnotetext{
${ }^{1}$ Graduanda do Curso de Licenciatura em Filosofia da Universidade Estadual do Piauí. E-mail: erisvandacampos@hotmail.com

${ }^{2}$ Graduanda do Curso de Licenciatura em Filosofia da Universidade Estadual do Piauí. E-mail: silmarasilvaphb@gmail.com
} 
determinada pela razão pura a priori, que se efetiva no agir de modo objetivo e universal, com fim em si mesmo.

Para Kant, "com efeito, a razão pode aqui pelo menos bastar para determinação da vontade e possuir sempre realidade objectiva quando unicamente se trata do querer" (KANT, 1995, p. 23) .Pois a ação moral não pode ser um meio para um fim, segundo uma boa vontade o fim da ação deve ser em si mesma, como uso da razão determinante da vontade como faculdade referente às representações livres, que determinam sua própria causalidade como resultado de uma pura vontade da razão prática.

$\mathrm{Na}$ Fundamentação da Metafísica dos Costumes o pensamento moral Kantiano busca estabelecer o fundamento do agir moral nas passagens das seguintes secções: Transição do conhecimento moral da razão vulgar para o conhecimento filosófico; transição da filosofia moral popular para a metafísica dos costumes; transição da metafísica dos costumes para a crítica da razão prática pura. Por essas passagens é possível perceber que a sistematização das secções percorre rumo ao estabelecimento dos princípios supremos da moralidade, o homem, a racionalidade, e a ação regida pela lei moral, sem ser submetidas às leis externas no sentido de inclinações, mas sim, numa moral que está fundamentada no próprio sujeito de modo a priori, em relação ao objeto (externo) da ação. Nesse sentido, é importante demonstrar que a existência da relação entre o agir moralmente e por dever, não pode ser determinada por ações de origem externas como inclinações do homem, mas por leis internas racionais e autônomas, para que a máxima de sua ação possa ser efetivada enquanto lei moral de modo objetivo, sendo a condição de possibilidade para uma lei universal, para uma ação comum a todos.

O homem pode querer agir de modo autônomo, construindo um pressuposto para suas próprias ações na objetivação das leis relacionadas, com sua capacidade de discernir sobre algo, pois o valor de uma ação parte de uma determinação direta da razão pura, que não é da mesma condição de uma razão especulativa que parte de princípios da experiência. Segundo a professora Sallyn Sedgwick, "Kant é explícito sobre o tipo de propósitos que não motivam uma boa vontade. Uma boa vontade não é motivada por objetos da faculdade da inclinação ou da faculdade de desejar" (SEDGWICK, 2017, p.151). Sendo o dever um mandamento direto da razão prática, é compatível ao valor de uma boa vontade, isto é, se faz na ação correta por que é o certo fazer. 
A autonomia em consonância as leis da liberdade são conjuntamente necessárias para a determinação do agir moral em sua dignidade, sem ser sob a faculdade da inclinação, mas por princípios a priori da razão, pois é por meio destes princípios da constituição de uma razão moral comum que serve como direção para uma razão prática, como formulação do dever-ser, que tem como determinação o imperativo categórico.

\title{
2. BOA VONTADE, DEVER E DIGNIDADE.
}

A boa vontade é uma categoria que pertence ao uso vulgar da razão, porém é preciso ser adequada para uma pura vontade, desta que será derivada o primeiro princípio para o conceito de dever e que posteriormente, a primeira fórmula do imperativo categórico. A boa vontade parte de uma distinção de uma razão moral comum para uma razão filosófica, que Kant apresenta na primeira secção, que é a transição do conhecimento moral da razão vulgar para o conhecimento filosófico que tem como objetivo investigar o conceito de boa vontade e suas denominações enquanto talentos e inclinações ou como princípios para uma pura vontade, o interesse de buscar entender estes conceitos de uma boa vontade e uma pura vontade se realiza no âmbito metafísico para uma condição prática pertencente ao querer do homem como possibilidade de uma ação boa em si mesma, portanto, uma boa vontade relaciona-se pelo ato do querer.

\begin{abstract}
A boa vontade não é boa por aquilo que promove ou realiza, pela aptidão para alcançar qualquer finalidade proposta, mas tão-somente pelo querer, isto é em si mesma, e, considerada em si mesma, deve ser avaliadora em grau muito mais alto do que tudo o que por seu intermédio possa ser alcançado em proveito de qualquer inclinação, ou mesmo, se quiser, da soma de todas as inclinações (KANT, 2007a, p.23).
\end{abstract}

A boa vontade ainda está sujeita a critérios empíricos apesar de ter princípios que sejam a priori, não é possível dizer que a boa vontade seja uma lei moral, mas somente a ação por dever, pois "Kant sustenta que faz parte de uma propensão específica da vontade humana a resistência de nossas inclinações à lei moral, e infere que a bondade da vontade para nós deve, com frequência, tomar a forma do agir por dever e que o motivo do dever é, portanto, uma parte proeminente e importante da vida moral” (WOOD, 2009, p.12). A ação praticada por dever não é 
uma ação para obtenção de algo, não é meio para se alcançar um fim, mas sim, uma ação por um fim em si mesma. A ação contrária ao dever é condicionada por um fim hipotético que privilegia a si próprio, subjetivo e particular, tornando-se, oposta a função do agir por dever. O princípio de uma ação determinada por dever é realizado por uma função a priori, objetiva e necessária, sem conceitos empíricos, mas, por conceitos a priori da razão, que tem como definição estabelecer máximas universais de leis morais para razão prática.

Princípios práticos são proposições que contém uma determinação geral da vontade, a qual inclui em si várias regras práticas. São subjectivos ou máximas quando a condição é considerada pelo o sujeito ou lei práticas quando essa condição é reconhecida como objectiva, isto é, válida para a vontade de todo um ser racional (KANT, 1995, p.29)

$\mathrm{Na}$ segunda secção, que é a transição da filosofia moral popular para a metafísica dos costumes, é possível identificar a máxima da lei moral por um querer, formulada pelo o imperativo categórico, constituída ainda por uma vontade, um querer por si mesmo e que diretamente está ligada ao dever e por meio disso, é viável dizer que tal ação é permitida ao imperativo categórico para que governe sua vontade, uma lei que rege a si mesmo de forma racional e a priori, "Age apenas segundo uma máxima tal que possas ao mesmo tempo querer que ela se torne lei universal" (KANT, 2007a, p.59). A Máxima da lei moral não é constituída por experiências empíricas condicionadas por elas mesmas, pois, se assim fosse, seriam conforme ao dever e não por dever, as ações conforme e contrárias ao dever não podem ser universais, pois não respeitam a lei moral. "Mesmo se "até agora" a experiência não forneceu uma prova sequer de que tenha havido, uma vez que seja, um amigo verdadeiramente sincero, a sinceridade na amizade é, não obstante, exigida de nós" (SEDGWICK, 2017, p.131). É relevante lembrar que a ação moral só é permitida por um dever incondicional, como um caráter de ordem a si mesmo, do próprio homem, ao contrário disso, poderia cair a uma falsa ideia de moralidade do "eu", como a postura do cético frente a tal ação sem motivos nobres, mas por si mesma ao motivar tais ações na prática.

Na realidade, é absolutamente impossível encontrar na experiência com perfeita certeza um único caso em que a máxima de uma acção, de resto conforme ao dever, se tenha baseado puramente em motivos morais e na representação do dever. Acontece por vezes na 
verdade que, apesar do mais agudo exame de consciência, não possamos encontrar nada, fora do motivo moral do dever, que pudesse ser suficientemente forte para nos impelir a tal ou tal boa acção ou a tal grande sacrifício (KANT, 2002, p.40).

A ação por dever está fora da influência de qualquer inclinação externa, a mesma possibilita a distinção entre o fim e o meio de uma determinada ação, pois ação deve ter o fim em si mesmo, e nunca ser meio para alcançar algo, pois, a pessoa na sua dignidade humana não é instrumento para atingir um fim e não deve ser atribuída a nenhum preço. Pois a pessoa possui seu devido valor ${ }^{3}$ enquanto pessoa. O imperativo categórico em umas de suas definições possui a seguinte máxima: "Age de tal maneira que uses a humanidade, tanto na tua pessoa como na pessoa de qualquer outro, sempre e simultaneamente como fim e nunca simplesmente como meio" (KANT, 2007a, p.69). Portanto, contemplando a definição de dignidade humana como fim em si mesmo e jamais como meio, independentemente de suas características casuais enquanto pessoas, mas pelo simples fato de serem pessoas, são dignas e autônomas que pertencem à mesma concepção de fim, mesmo que, no entanto, não façam uso da razão por causalidades externas ou internas.

O homem em sua dignidade não pode ser tratado como meio para uma finalidade, mas como fim em si mesmo, pois se deve considerar a condição de leis a priori na ação puramente moral no valor que é sua dignidade e ação moral por dever, "Ora a moralidade é a única condição que pode fazer de um ser racional um fim em si mesmo, pois só por ela lhe é possível ser membro legislador no reino dos fins. Portanto a moralidade, e a humanidade enquanto capaz de moralidade são as únicas coisas que têm dignidade" (KANT, 2007a, p.78). Para Kant o conceito de dignidade está inserido no contexto da ação moral e por dever, Kant desenvolve uma moral pautada no homem e na razão, pois o homem é o único animal capaz de possuir a faculdade de liberdade por ser racional e autônomo, portanto, pode agir e se governar livre das demandas da sensibilidade, tornando suas ações incondicionadas sem influências externas e hipotéticas. Agir incondicionalmente

\footnotetext{
${ }^{3}$ Valor para Kant (2007a, p. 78) designa uma dimensão intrínseca da pessoa humana, pois, somente as pessoas concernem ao valor acima de tudo e por esse motivo, não há nenhum preço e jamais deve haver sob as pessoas.
} 
significa não agir com a condição para alcançar algo, mas, sim por causa de um dever.

A dignidade do homem concerne à ideia de que o homem é um fim em si mesmo e não um meio, portanto, ele não pode ser condição para algo, pois possui em si a faculdade de liberdade e a razão. A ideia de dignidade também está relacionada à felicidade, além de estar na ação por um fim em si mesmo, portanto na ação moral. A moralidade constitui-se, na própria condição da dignidade e sucessivamente na própria condição de felicidade.

\section{A AÇÃO POR RESPEITO À LEI MORAL}

A ação moral é ordenada por dever determinada pelo imperativo categórico, à vontade no cumprimento ao dever é sempre por respeito à lei moral, é exatamente por isso, que a ação deve partir de um querer particular enquanto lei moral, para a possibilidade de ser universalizada, "Devo proceder sempre de maneira que eu possa querer também que a minha máxima se torne uma lei universal" (KANT, 2007a, p.33). É necessário que o homem aja de tal forma que esteja desprovido de qualquer ação que o leve fazer por algum privilégio ou apego, em outras palavras, por conformidade, a ação conforme a lei não possui nenhum valor que tenha a pretensão de ser moral e universalizada e por esse motivo Kant ressalta que a ação deve ser objetiva em um juízo determinante de caráter objetivo e não subjetiva conduzida por inclinações externas.

Eu afirmo, porém que neste caso tal acção, por conforme o dever, por amável que ela seja não tem, contudo nenhum verdadeiro valor moral, mas vai emparelhar com outras inclinações, por exemplo, o amor das honras que, quando por feliz acaso topa aquilo que efetivamente é de interesse geral e conforme o dever, é consequentemente honroso e merece louvor e estímulo, mas não estima; pois à sua máxima falta o conteúdo moral que manda que tais acções se pratiquem, não por inclinações, mas por dever (KANT, 2007a, p. 113).

Obedecer à lei moral é o mesmo que agir por meio de uma faculdade de auto-avaliação da postura do sujeito, este que tem como dever o sentimento que é aceitável e indispensável para o cumprimento do mesmo, o respeito ao dever, a qual a ação se realiza como máxima em si, pois ela é feita por dever e por respeito à lei. 
Dever é a necessidade de uma acção por respeito à lei. Pelo objecto, como efeito da acção em vista, posso eu sentir em verdade, inclinação, mas nunca respeito, exactamente porque é simplesmente um efeito e não a actividade de uma vontade" (KANT, 2007a, p.31)

À vontade como razão a priori se realiza no uso da razão prática e por meio dela determina a ação e as vontades externas referentes às inclinações, é através da ação por dever que o homem passa ser legislador de sua própria lei, na determinação da máxima do imperativo categórico. "O imperativo categórico seria aquele que nos representasse uma acção como objetivamente necessária por si mesma, sem relação com qualquer outra finalidade" (KANT, 2007a, p.50). Ou seja, para que a ação possa ser realizada como síntese de formalidade universal, como objetivo fazer o sujeito detentor da consciência do puro dever, de uma ação necessária e por si mesma.

O respeito ao dever é formal para si mesma e para com o outro, não infligindo naquilo que é externo e pertencente a ele próprio, mas a própria ação. "A ação é realizada não apenas conforme um princípio objetivo de determinação válido universalmente, mas também pelo dever, com um sentimento de respeito pela própria lei moral" (TERRA, 2004, p.14).O homem na ação por dever, que é o próprio imperativo categórico tem como condição sua própria liberdade e a vontade como representação da lei moral, tendo como máxima em comum para universalidade.

\section{AÇÃO POR DEVER E IMPERATIVO CATEGÓRICO}

O imperativo categórico é uma proposição "sintética a priori" que provém de uma vontade livre e em si mesma, sem inclinações externas, o dever categórico de uma ação tem a devida importância na determinação frente à possibilidade da razão prática na síntese da concepção de dignidade humana, pois, é por meio da ação por dever que se torna possível a ordenação da dignidade humana enquanto entendimento e razão prática na autonomia do sujeito constituidor e avaliador de si mesmo.

O Imperativo categórico como proposição sintética e a priori é formulada dentro de uma lógica transcendental para uma prática universal, onde o sujeito frente ao objeto não o deixa determiná-lo, mas sim, pela a própria razão como entendimento e conhecimento da sua natureza, não por ações empíricas, mas, por intuições de representações como condição do próprio entendimento humano para as proposições por formuladas por dever a lei moral. 
E esse dever categórico representa uma proposição sintética a priori, porque acima da minha vontade afectada por apetites sensíveis sobrevêm ainda a ideia dessa mesma vontade, mas como pertencente ao mundo inteligível, pura, prática por si mesma, que contém a condição suprema da primeira, segundo a razão; mais ou menos como às intuições do mundo sensível se juntam conceitos do entendimento, os quais por si mesmos nada mais significam senão a forma de lei em geral, e assim tornam possíveis proposições sintéticas a priori sobre as quais repousa todo o conhecimento de uma natureza (KANT, 2007a, p.104).

O dever como máxima da lei universal se faz pela a lei no campo da moral e prática, como possibilidade de condição própria do homem e sua autonomia, o homem que conhece somente o fenômeno e que pertence ao espaço e tempo, faculdade de entendimento e não o nôumenon que é atemporal, mas que, no entanto, pode ser pensado, "a coisa em si" o sujeito perante as sensações externas como inclinações, não podem ser determinantes para o homem, é a razão que determina e tem a possibilidade de investigação frente o que é externo, como potencialidade de uma lei moral.

A pura vontade é pré-orientada para uma ação, a partir da reflexão e autoreflexão de determinar e constituir máximas como condição da liberdade transcendental e autônoma, firmada em uma ética por dever é constituída pela própria capacidade racional do homem como lei universal sintética e a priori.

O conceito segundo o qual todo o ser racional deve considerar-se como legislador universal por todas as máximas da sua vontade para, deste ponto de vista, se julgar a si mesmo e às suas acções, leva a outro conceito muito fecundo que lhe anda aderente e que é o de um Reino dos Fins. Por esta palavra reino entendo eu a ligação sistemática de vários seres racionais por meio de leis comuns. Ora como as leis determinam os fins segundo a sua validade universal, se se fizer abstracção das diferenças pessoais entre os seres racionais e de todo o conteúdo dos seus fins particulares, poder-se-á conceber um todo do conjunto dos fins (tanto dos seres racionais como fins em si, como também dos fins próprios que cada qual pode propor a si mesmo) em ligação sistemática, quer dizer, um reino dos fins que seja possível segundo os princípios acima expostos (KANT, 2007a, p.75- 76).

A pessoa na sua capacidade reflexiva e sem influências externas possa constituir suas próprias ações e verificá-las e modificá-las como possibilidade de 
auto-correção, cabível pensar pelo princípio de dever categórico que é de âmbito universal e necessário, uma formulação para o pensamento crítico do sujeito, pensar a ética e as ações que norteiam esse pensamento, equivale a pressupostos éticos para fundamentação de direitos e princípios morais diferentes dos postulados ${ }^{4}$ da razão prática, mas sim, uma lei que determina a vontade de uma ação.

\section{CONSIDERAÇÕES FINAIS}

A liberdade constitui a dignidade da pessoa humana, da qual não pode jamais se refere como meio ou coisa, no sentido de que, é inerente tal autonomia, independente de causalidade externas da pessoa, ou até mesmo internas, pois isto não retira seu valor enquanto pessoa humana, enquanto sua dignidade, enquanto $o$ fim em si mesmo, ainda que não seja provida da faculdade de entendimento, porém, é evidente que os demais em suas faculdades possam fazer uso da razão em detrimento ao dever moral e discernir tais posturas frente às demais situações.

Por este motivo é relevante pensar que tal pessoa humana em seu pleno uso da razão pode determinar a ação moral, ou melhor, um dever moral como máxima sintética e a priori, como condição de possibilidade de constituir uma lei moral comum a todos, não por um vir a ser, em busca de fins, mas por um Dever-ser como fim em si mesmo. O imperativo categórico que é universalmente e necessário por si só, isto é, que faz o homem ser digno de tal autonomia perante a si mesmo posterior à humanidade, como condição de estabelecer uma ação moral por lei, um novo princípio causal para o mundo humano que se direcionar para um "reino dos fins"

\section{REFERÊNCIAS}

KANT, Immanuel. Fundamentação da Metafísica dos Costumes. Tradução: Paulo Quintela. Lisboa: Edições 70, Lda, 2007a.

\section{Ideia de uma história universal com um propósito cosmopolita.}

Tradução: Paulo Quintela. Lisboa: Edições 70, 2007b.

. Crítica da Razão Prática. Tradução: Artur Morão. Lisboa: Edições 70, 1995.

. Crítica da Razão Pura. Tradução: Valério Rohden e UdoBaldurMoosburger. São Paulo: Abril Cultural, 2005. - (Coleção Os Pensadores).

\footnotetext{
${ }^{4}$ São proposições relativas à liberdade, imortalidade da alma e Deus, que não são dogmas teóricos, mas pressupostos de sentido prático que podem formular conceitos como projeção para uma realidade objetiva como possibilidade afirmativa.
} 
MARITAIN, Jacques. A filosofia moral. Tradução: Alceu Amoroso Lima. Rio de Janeiro: Edições Agir, 1964.

SANDEGWICK, Sally. Fundamentação da metafisica dos costumes: Uma chave de leitura. Tradução de Diego Kosbiau Trevisan. - Petrópolis, Rio de Janeiro: Vozes, 2017. - (Coleção chaves de leituras).

TERRA, Ricardo R. Kant \& o direito / Ricardo Terra. - Rio de Janeiro: Jorge Zahar Ed., 2004.

WOOD, Allen. A boa vontade. Tradução: Vera Cristina de Andrade Bueno. Studia Kantiana, Revista da Sociedade Kant Brasileira, Santa Maria, v.9, 2009, p.7-40. 